Original articles

\title{
Estimating the environmental Kuznets curve for ecological footprint at the global level: A spatial econometric approach
}

\author{
Yong Wang, Lingyan Kang*, Xiaoqing Wu, Yang Xiao \\ Key Laboratory of Coastal Zone Environmental Processes and Ecological Remediation, Yantai Institute of Coastal Zone Research, \\ Chinese Academy of Sciences, Yantai Shandong 264003, PR China
}

\section{A R T I C L E I N F O}

\section{Article history:}

Received 1 August 2012

Received in revised form 20 January 2013

Accepted 16 March 2013

\section{Keywords:}

Environmental Kuznets curve

Ecological footprint

Biocapacity

Spatial dependence

Spatial error model

Spatial Durbin model

\begin{abstract}
A B S T R A C T
The national ecological footprint of both consumption and production are significantly spatially autocorrelated at global level. This violates the assumption of independently distributed errors of most conventional estimation techniques. Using a spatial econometric approach, this paper re-examine the relationship between economic growth and environmental impact for indicator of ecological footprint. The results do not show evidence of inverted U-shape Environmental Kuznets Curve. The domestic ecological footprint of consumption (or production) was obviously influenced by the ecological footprint of consumption (or production), income and biocapacity in neighborhood countries. We also found that the consumption footprint is more sensitive to domestic income, while production footprint is more sensitive to domestic biocapacity, which is often unnoticed in EKC hypothesis analyses that focus exclusively on the consumption-based or production-based indictors.
\end{abstract}

(C) 2013 Published by Elsevier Ltd.

\section{Introduction}

Over the past decades, there has been considerable interest in analyzing the relationship between economic growth and environmental impact. They have tried to find out whether or not environmental pressure is rising with national income at low income levels, but falling at higher income levels. If the underlying phenomenon exists, such an inverted U-shaped relationship between economic growth and environmental impact is known as the Environmental Kuznets Curve (EKC). Since the early 1990s, heated debates have been made on the EKC hypothesis, and plenty of empirical studies support the inverted-U relationship (Beckerman, 1992; Shafik and Bandyopadhyay, 1992; Cropper and Charles, 1994; Selden and Song, 1995; Grossman and Krueger, 1996; Panayotou, 1999; Canas et al., 2003; Roca, 2003; McPherson and Nieswiadomy, 2005; Liu et al., 2007). According to several empirical studies, technological innovation, structural change toward information-intensive industries and services, increased environmental awareness and higher environmental expenditures play important roles in shaping the EKC (Grossman and Krueger, 1996; Suri and Chapman, 1998; Vukina et al., 1999; Antweiler et al., 2001; Liddle, 2001; Pasche, 2002; Cole, 2004; Auci and Becchetti, 2006). However, more and more recent researches have cast doubt

\footnotetext{
* Corresponding author. Tel.: +86 535 2109039; fax: +86 5352109000.

E-mail addresses: yongwang@yic.ac.cn (Y. Wang), lykang@yic.ac.cn (L. Kang).
}

on the concept of empirical results, and evidence of the existence of the EKC has also been questioned (Rothman, 1998a; Grether and Melo, 2002; Roca, 2003; Dinda, 2004; Bagliani et al., 2008; RomeroAvila, 2008; Kearsley and Riddel, 2010). Some evidence shows that if there was an inverted U-shaped relationship it might be partly or largely a result of the effects of trade on the distribution of polluting industries (Arrow et al., 1995; Stern, 2004). More specifically, International trade provides the means by which 'dirty' industries can be moved from the developed regions to the developing regions (Cole, 2004).

EKC has now been estimated for a variety of environmental indictors including air pollution, water pollution, deforestation, hazardous waste and toxins, carbon dioxide, biodiversity conservation and ecological footprint (Shafik and Bandyopadhyay, 1992; Kaufmann et al., 1998; Rothman, 1998a; Bhattarai and Hammig, 2001; Stern, 2004; Galeotti et al., 2006; Managi, 2006; Culas, 2007; Bagliani et al., 2008; Caviglia-Harris et al., 2009; Leitao, 2010). At its most basic the technique involves regressing per capita emissions or concentrations on income per capita and its squared value with panel data (Maddison, 2006). Although panel data are more informative and have greater degrees of freedom, spatial dependence is a problematic aspect of many panel data sets in which the cross-sectional units are not randomly sampled. Usually, one observation in a sample of cross-sectional observations depends on other cross-sectional observations (Rupasingha, 2009). Anselin and Griffith (1988) describe this as the existence of a functional relationship between what happens at one point in space and what 
happens elsewhere, which violates standard statistical techniques that assume independence among observations.

Spatial effects are important in evaluating the impact of economic growth on environmental quality (Giacomini and Granger, 2004). On the one hand, many of the subjects in the environmental issues are inherently spatial. The spread of contaminated water, the diffusion of air pollution, and the spread of invasive species all lead to the spatial autocorrelation problem in statistics (Raymond and Arno, 2003). In reality, most data sets used to estimate EKC contain elements of both being composed of repeated observations on countries (Maddison, 2006). On the other hand, countries can interact strongly with each other through channels such as trade, technological diffusion, capital inflows, and common political, economic and environmental policies (Ramirez and Loboguerrero, 2002). Some studies have suggested that the shape of the EKC is a consequence of high-income countries in effect exporting their pollution to lower-income countries through international trade (Cole, 2004). In such cases, externalities can spillover the limits among countries, contributing in the explanation of environmental effects of economic growth. Anselin and Rey (1991) recognized such forms of spillover effects as cases of substantial spatial dependence and ignoring these spatial relationships would weaken our ability to generate meaningful inferences about the processes we study.

Several authors have recently pointed to the importance of spatial dimensions in environmental measures (Bockstael, 1996; Goodchild et al., 2000; Anselin, 2001; George and Nickolaos, 2011). According to Cliff and Ord (1981), while causal factors form an essential part of the underlying process, the inclusion of spatial components is likely to be important to an understanding of the problem analyzed. Even from an analytical perspective, these spatial effects are also important because they may invalidate certain standard methodological results (Anselin and Rey, 1997; Anselin, 1988; Ying, 2003). Raymond and Arno (2003) pointed out that once spatial dependency had been discovered, it is obviously a need to specify a spatial statistical model accounting for such spatial effects and to use an appropriately spatially adapted estimator. Spatial regression models provide ways to test and accommodate various forms of dependence among observations. Following, among others, the pleas of Bockstael (1996) and Anselin (2001) to explicitly incorporate space in the analysis of environmental topics, a small literature is now emerging. Nowadays, spatial econometric models have begun to make inroads into the study of environmental policy and natural resource management.

Although cross-sectional units or geographical areas form the basic unit of analysis in most EKC studies, the spatial data analysis techniques was underused in this topic for a long time. Ignoring spatial considerations may lead to incorrect inferences and poor model performance. This particular shortcoming has been recognized by Rupasingha et al. (2004), who first incorporate spatial correlation structures into analysis of the relationship between per capita income and toxic pollution in the US counties. Then the spatial econometric analysis of the EKC is gradually starting off by considering air pollutants (Maddison, 2006) and species imperilment (McPherson and Nieswiadomy, 2005; Pandit and Laband, 2007). However, to our knowledge, there have no reports about applications of the spatial econometric technique to examine the EKC for ecological footprint, a powerful indicator for measuring and communicating environmental impact and sustainable resource use. Maddison (2006) suggested that further studies of the EKC using spatial econometric approach are still necessary to better understand the unobserved spatial dependence across countries.

The objectives of this paper were thus to explore systematically the use of spatial econometric techniques in estimating EKC for ecological footprint. We begin with a conventional EKC estimation to find a linear relationship between dependent and independent variables and get a range of diagnostics for spatial autocorrelation description. Then, this paper expands the analysis by incorporating spatial variables in our models and re-examining the claim for the EKC. In addition, the difference in the spatial correlation of national ecological footprints between consumption and production has been performed finally.

\section{Methods and materials}

\subsection{Methods}

Cross sectional data are often associated with each other, this is a spatial autocorrelation. Specification testing for spatial autocorrelation is typically performed with the asymptotic distribution of Moran's I test statistic, which depends on the spatial weight matrices that reflect the intensity of the geographic relationship between observations in a neighborhood (Anselin and Bera, 1998). Methodological background for Moran's I test statistic and spatial weight construction can be found in many econometrics texts and will not be covered here.

Spatial econometric models may present themselves in a variety of types. Models can be estimated with cross-sectional as well as panel data. Inadequacies in the available data relating to the footprint and biocapacity accounts for all the countries involved in our analysis in time series having led to the condition that the cross sectional models are the approach that I would take throughout the remainder of the paper. Two types of cross sectional models have been used: spatial lag models and spatial error models. The spatial lag model in matrix form is given by:

$Y=\alpha+\rho W Y+X \beta+\varepsilon$

where $Y$ is a vector of dependent variables, $X$ is a matrix of explanatory variables, $W$ is the spatial weight matrix, $\alpha$ and $\rho$ are scalar parameters, $\beta$ is a vector of parameters and $\varepsilon$ is a normally distributed disturbance term with a diagonal covariance matrix.

An alternative way of incorporating spatial relationships is through spatial dependence in the error term. This refers to a situation in which the errors associated with any one observation are a spatially weighted average of the errors at nearby sites plus a random error component. The spatial error model is given by:

$Y=\alpha+X \beta+\varepsilon, \quad \varepsilon=\lambda W \varepsilon+u$

where $\lambda$ is the autoregressive coefficient.

Maddison (2006) proposes that the spatial error model can also be approximated by an autoregressive lag in both the dependent and independent variables. Then we extend the model in (2) to a spatial Durbin form, which is written as:

$Y=\rho W Y+X \beta_{1}+W X \beta_{2}+\varepsilon$

where $\beta_{1}$ and $\beta_{2}$ are the associated parameter vectors.

The model shown in (3) is referred to as a spatial Durbin model by Anselin (1988) due to the analogy with a suggestion by Durbin for the case of a time series model with residual autocorrelation (LeSage, 1999). Spatial regression models cannot be estimated by OLS estimators for the problem of residual covariance. It must instead be estimated using maximum likelihood techniques. In this analysis, the Moran's I test statistic, spatial lag and error models were estimated using GeoDa 0.9.5-I, and spatial Durbin models were estimated using LeSage's Spatial Econometrics MATLAB toolbox.

\subsection{Materials}

The Ecological Footprint Atlas 2008 (Ewing et al., 2008) developed by Global Footprint Network, provide a detailed accounting 
Table 1

Descriptive statistics.

\begin{tabular}{|c|c|c|c|c|}
\hline Variable & Mean & Minimum & Maximum & Standard deviation \\
\hline EFC (global hectares per capita) & 2.6658 & 0.4713 & 9.4597 & 1.9732 \\
\hline EFP (global hectares per capita) & 2.7387 & 0.4100 & 13.1100 & 2.4639 \\
\hline BIO (global hectares per capita) & 3.1173 & 0.0346 & 24.9731 & 3.9436 \\
\hline GDP (constant 2000 international $10^{3} \$$ ) & 8.7879 & 0.3117 & 37.2673 & 9.5654 \\
\hline
\end{tabular}

EFC: The national Ecological Footprint of Consumption per capita.

EFP: The national Ecological Footprint of Production per capita.

BIO: The national Biocapacity per capita.

GDP: The national Gross Domestic Product per capita.

of ecological footprint of consumption and production for the year 2005 for 150 nations with populations over 1 million. The consumption footprint of a country measures the biocapacity demanded by the final consumption of all the residents of the nation. This includes their household consumption, as well as their collective consumption (such as schools, roads, fire brigades, etc.) that serves the household, but may not be directly paid for by the households. By contrast, the production footprint of a country is the sum of the footprints for all resources harvested and all waste generated within the nation's geographical borders. This includes all the area within a country necessary for supporting the actual harvest of primary products, the country's built-up area, and the area needed to absorb all fossil fuel carbon emissions generated within the country. The difference between the two variables is the footprint of imports and exports. These footprints are measured in global hectares (gha).

Gross Domestic Product and population data for year 2005 for each country come from the World Development Indicators 2007 database (World Bank, 2007). Monetary figures are expressed in PPP constant 2000 international \$. Besides income, we hypothesize that biocapacity in a country is directly related to the footprint of consumption or production, since the ecological resources use is potentially affected by the biocapacity locally available in any given country. Bagliani et al. (2008) found that biocapacity had a significant effect on ecological footprint, and Bertinellia et al. (2008) also found such a relationship with respect to the consumption of natural resources. The biocapacity per person for each country are taken from the Ecological Footprint Atlas 2008. Descriptive statistics of variables used in this study are presented in Table 1.

In our analysis, three spatial weight matrices were constructed using the GeoDA software. The first matrix is constructed based on a simple or first contiguity criterion which defines neighbors as locations that share either a border or a vertex in their boundaries. The second matrix is created based on the concept of the higher order contiguity which includes the first and second order neighbors. The third matrix is a distance-based spatial weight which defines countries to be neighbors if the distance between their centroids is less than the threshold distance. In order to ensure every country must have at least one neighbor, following Maddison (2006), here we set 1750 miles as the threshold distance.

\section{Results and discussion}

\subsection{Spatial autocorrelation tests}

Table 2 presents the results relative to the Moran's I tests for spatial autocorrelation in ecological footprint and biocapacity. For the Moran's I, the $z$-values are positive and highly significant, indicating the presence of spatial autocorrelation in ecological footprint and biocapacity. Among all the spatial weights, the values of Moran's I based on the simple adjacency matrix, 0.4673 and 0.4701 for consumption footprint and production footprint respectively, are the highest, suggesting countries with high ecological footprint of consumption or production tend to have neighbors that also have high ecological footprint of consumption or production, and conversely countries with low ecological footprint of consumption or production "cluster together" with other low ecological footprint of consumption or production countries.

\subsection{OLS regression with diagnostics}

Although spatial autocorrelation violates the assumption of independence of observations which is a serious concern for traditional hypothesis tests, we still first run an OLS estimation so as to provide results comparing with those of spatial regression models in later sections. Table 3 presents our estimation results.

At conventional levels all cubic income terms for the two indicators of the environmental stress are statistically insignificant. Removing the statistically insignificant higher-order terms of income per capita exhibits a different pattern of relationship between economic growth and environmental stress. For the production it appears that ecological footprint is likewise increasing with respect to income levels over virtually the whole range of per capita income, while for the consumption it seems to show an inverted-U type of behavior that might support the EKC hypothesis. As shown in Table 3, the income quadratic term is statistically significant (at $1 \%$ level) only for the ecological footprint of consumption. In contrast, the biocapacity is significantly playing positive roles in explaining the increase of ecological footprint of both consumption and production. The coefficients of model 2 and 4 imply that a one percent increase in biocapacity leads to a $0.25 \%$ increase

Table 2

Tests of spatial autocorrelation.

\begin{tabular}{|c|c|c|c|c|c|}
\hline Variable & Spatial weight matrix & Moran's I & $Z$-value & Standard deviation & $P$-value \\
\hline \multirow[t]{3}{*}{ EFC } & Simple adjacency & 0.4673 & 9.2220 & 0.0514 & 0.0000 \\
\hline & Higher adjacency & 0.3827 & 8.6344 & 0.0451 & 0.0000 \\
\hline & Countries within 1750 miles & 0.3521 & 8.5840 & 0.0418 & 0.0000 \\
\hline \multirow[t]{3}{*}{ EFP } & Simple adjacency & 0.4701 & 9.2405 & 0.0516 & 0.0000 \\
\hline & Higher adjacency & 0.3066 & 7.4069 & 0.0423 & 0.0000 \\
\hline & Countries within 1750 miles & 0.3007 & 7.3720 & 0.0417 & 0.0000 \\
\hline \multirow{3}{*}{ BIO } & Simple adjacency & 0.3582 & 6.5047 & 0.0561 & 0.0000 \\
\hline & Higher adjacency & 0.1803 & 5.3739 & 0.0348 & 0.0000 \\
\hline & Countries within 1750 miles & 0.1793 & 6.6433 & 0.0280 & 0.0000 \\
\hline
\end{tabular}


Table 3

The ordinary least-squares regression models for ecological footprint of consumption and production.

\begin{tabular}{|c|c|c|c|c|c|c|}
\hline & \multicolumn{3}{|l|}{ EFC } & \multicolumn{3}{|l|}{ EFP } \\
\hline & Model 1 & Model 2 & Model 3 & Model 4 & Model 5 & Model6 \\
\hline Constant & $0.9296^{* * *}$ & $0.6817^{* * *}$ & $0.6002^{* * *}$ & $0.4076^{* *}$ & 0.2103 & 0.0851 \\
\hline GDP & $0.1727^{* * *}$ & $0.2487^{* * *}$ & $0.2912^{* * *}$ & $0.1778^{* * *}$ & $0.2384^{* * *}$ & $0.3035^{* * *}$ \\
\hline $\mathrm{GDP}^{2}$ & & $-0.0025^{* *}$ & -0.0061 & & -0.0019 & -0.0075 \\
\hline $\mathrm{GDP}^{3}$ & & & $7.3508 \times 10^{-5}$ & & & $11.7162 \times 10^{-5}$ \\
\hline $\mathrm{BIO}$ & $0.0702^{* * *}$ & $0.0700^{* * *}$ & $0.0690^{* * *}$ & $0.2464^{* * *}$ & $0.2463^{* * *}$ & $0.2447^{* * *}$ \\
\hline Observations & 150 & 150 & 150 & 150 & 150 & 150 \\
\hline $\mathrm{R}^{2}$ & 0.7658 & 0.7754 & 0.7750 & 0.7415 & 0.7443 & 0.7442 \\
\hline Log-likelihood & -204.424 & -200.752 & -200.392 & -245.112 & -243.781 & -243.303 \\
\hline AIC & 414.848 & 409.504 & 410.784 & 496.225 & 495.561 & 496.606 \\
\hline SC & 423.879 & 421.547 & 425.837 & 505.257 & 507.604 & 511.659 \\
\hline
\end{tabular}

${ }^{*} p<0.05$.

${ }^{* *} p<0.01$.

*** $p<0.001$.

in ecological footprint of production and $0.07 \%$ increase in ecological footprint of consumption.

The OLS estimation models may to a certain extent reveal the relationships between dependent and independent variables. However, given the presence of spatial autocorrelation in the ecological footprints, a maximum likelihood estimation of the spatial lag or error model would be an appropriate way to proceed. In order to determine which spatial specification should be used, a variety of tests have been performed based on the least-squares residuals and the spatial weights matrices (Table 4). Results indicate that the spatial error dependence has been present in the linear models (model 1 and 4) for the two environmental indictors. As shown in Table 4, both the ordinary and robust LM test for a spatial error dependence based on adjacency matrix are statistically significant (at $1 \%$ level for the production footprint and at $5 \%$ level for the consumption footprint). In contrast, the threshold distancebased ordinary LM error tests are statistically significant only at $10 \%$ level. With regard to the quadratic model for the consumption footprint, only the ordinary LM tests for a spatial error based on adjacency matrix are statistically significant (at 10\% level). Following the rules of model selection suggested by Anselin (2005), the spatial error model should be employed to capture the geographic spillover effects showing in the panel data of ecological footprint.

\subsection{Spatial regression}

Table 5 gives the results of the maximum likelihood estimation of the spatial error models and measures. The first thing to note is that all of the spatial autocorrelation coefficients $(\lambda)$ are high statistically significant, indicating that the spatial dependence presenting in the data settings has been captured by the spatial error modes. It seems that the coefficient estimate of the OLS model assuming independent observations may display substantial bias. As a result, the income quadratic term for the ecological footprint of consumption, which was statistically significant in the OLS regression, becomes insignificant at conventional levels once taking into account the spatial dependence. Therefore, we found no evidence of an inverted U-shaped relationship between per capita income

Table 4

Diagnostics for spatial dependence for the least-squares residuals of model 1-6.

\begin{tabular}{|c|c|c|c|c|c|c|}
\hline & \multicolumn{3}{|l|}{$\mathrm{EFC}$} & \multicolumn{3}{|l|}{ EFP } \\
\hline & Model 1 & Model 2 & Model 3 & Model 4 & Model 5 & Model 6 \\
\hline \multicolumn{7}{|c|}{ Spatial weight matrix $=$ simple adjacency } \\
\hline \multirow[t]{2}{*}{ LM lag } & 0.9512 & 0.7281 & 0.5591 & 3.0823 & 3.2846 & 2.6961 \\
\hline & Prob $=0.3294$ & Prob $=0.3935$ & Prob $=0.4546$ & Prob $=0.0792$ & Prob $=0.0699$ & Prob $=0.1006$ \\
\hline \multirow[t]{2}{*}{ Robust LM lag } & 0.0827 & 0.1328 & 0.0666 & 1.5887 & 1.0070 & 1.2632 \\
\hline & Prob $=0.7737$ & Prob $=0.7155$ & Prob $=0.7963$ & Prob $=0.2075$ & Prob $=0.3156$ & Prob $=0.2611$ \\
\hline \multirow[t]{2}{*}{ LM error } & 5.2133 & 1.0838 & 1.0271 & 20.9697 & 19.1971 & 17.9112 \\
\hline & Prob $=0.0224$ & Prob $=0.2978$ & Prob $=0.3108$ & Prob $=0.0000$ & Prob $=0.0000$ & Prob $=0.0000$ \\
\hline \multirow[t]{2}{*}{ Robust LM error } & 4.3448 & 0.4886 & 0.5346 & 19.5584 & 16.9194 & 16.4783 \\
\hline & Prob $=0.0371$ & Prob $=0.4846$ & Prob $=0.4647$ & Prob $=0.0000$ & Prob $=0.0000$ & Prob $=0.0000$ \\
\hline \multicolumn{7}{|c|}{ Spatial weight matrix = higher adjacency } \\
\hline \multirow[t]{2}{*}{ LM lag } & 1.6630 & 1.1376 & 0.9438 & 0.2978 & 0.1908 & 0.0763 \\
\hline & Prob $=0.1972$ & Prob $=0.2862$ & Prob $=0.3313$ & Prob $=0.5853$ & Prob $=0.6623$ & Prob $=0.7824$ \\
\hline \multirow[t]{2}{*}{ Robust LM lag } & 0.1373 & 0.2509 & 0.1789 & 2.4721 & 2.1968 & 2.4337 \\
\hline & Prob $=0.7110$ & Prob $=0.6121$ & Prob $=0.6723$ & Prob $=0.1159$ & Prob $=0.1383$ & Prob $=0.1188$ \\
\hline \multirow[t]{2}{*}{ LM error } & 5.9468 & 2.5092 & 2.3738 & 18.5035 & 15.5952 & 14.0420 \\
\hline & Prob $=0.0147$ & Prob $=0.1132$ & Prob $=0.1234$ & Prob $=0.0000$ & Prob $=0.0001$ & Prob $=0.0002$ \\
\hline \multirow[t]{2}{*}{ Robust LM error } & 4.4211 & 1.6288 & 1.6089 & 20.6778 & 17.6013 & 16.3993 \\
\hline & Prob $=0.0354$ & Prob $=0.2019$ & Prob $=0.2046$ & Prob $=0.0000$ & Prob $=0.0000$ & Prob $=0.0000$ \\
\hline \multicolumn{7}{|c|}{ Spatial weight matrix $=$ countries within 1750 miles } \\
\hline \multirow[t]{2}{*}{ LM lag } & 1.4162 & 0.8726 & 0.5926 & 1.1602 & 1.0275 & 0.5791 \\
\hline & Prob $=0.2340$ & Prob $=0.3502$ & Prob $=0.4414$ & Prob $=0.2814$ & Prob $=0.31108$ & Prob $=0.4467$ \\
\hline \multirow[t]{2}{*}{ Robust LM lag } & 0.3052 & 0.1953 & 0.0449 & 0.1155 & 0.0810 & 0.0087 \\
\hline & Prob $=0.5806$ & Prob $=0.6585$ & Prob $=0.8322$ & Prob $=0.7340$ & Prob $=0.7760$ & Prob $=0.9259$ \\
\hline \multirow[t]{2}{*}{ LM error } & 3.0804 & 1.9377 & 2.2296 & 3.3325 & 3.3015 & 2.5485 \\
\hline & Prob $=0.0792$ & Prob $=0.1639$ & Prob $=0.1354$ & Prob $=0.0679$ & Prob $=0.0692$ & Prob $=0.1104$ \\
\hline \multirow{2}{*}{ Robust LM error } & 1.9694 & 1.2603 & 1.6820 & 2.2879 & 2.3550 & 1.9780 \\
\hline & Prob $=0.1605$ & Prob $=0.2616$ & Prob $=0.1947$ & Prob $=0.1304$ & Prob $=0.1249$ & Prob $=0.1596$ \\
\hline
\end{tabular}


Table 5

Spatial error models for ecological footprint of consumption and production.

\begin{tabular}{|c|c|c|c|c|}
\hline & EFC & & EFP & \\
\hline Constant & $0.6704^{* *}$ & $0.7150^{* *}$ & $0.5341^{*}$ & 0.4548 \\
\hline GDP & $0.1903^{* * *}$ & $0.1475^{* * *}$ & $0.1779^{* * *}$ & $0.2181^{* * *}$ \\
\hline $\mathrm{GDP}^{2}$ & & -0.0015 & & -0.0013 \\
\hline $\mathrm{BIO}$ & $0.0762^{* *}$ & $0.0822^{* * *}$ & $0.0791^{* * *}$ & $0.0762^{* * *}$ \\
\hline$\lambda$ & $0.7181^{* * *}$ & $0.7923^{* * *}$ & $0.9449^{* * *}$ & $0.8414^{* * *}$ \\
\hline Observations & 150 & 150 & 150 & 150 \\
\hline Log-likelihood & -198.7529 & -198.7528 & -199.1159 & -197.9332 \\
\hline AIC & 403.5060 & 405.5060 & 404.2320 & 403.8660 \\
\hline SC & 412.5378 & 417.5483 & 413.2637 & 415.9090 \\
\hline Likelihood ratio & $10.6156^{* *}$ & $5.6375^{*}$ & $29.1717^{* * *}$ & $49.4147^{* * *}$ \\
\hline
\end{tabular}

Spatial weight matrix = higher adjacency.

${ }^{*} p<0.05$.

*** $p<0.01$.

*** $p<0.001$.

and ecological footprint of consumption. It appears that a monotonic increase is the best fitting trend for ecological footprint of both consumption and production. These results strongly suggest that the spatial relationships play an important role in shaping the income-footprints relationship and ignoring the spatial effects should be responsible to the failure of OLS estimations.

The value of $R^{2}$ listed in the spatial regression output is not a real measure of fit, but a so-called pseudo- $R^{2}$, which is not directly comparable with the measure given for OLS results. Instead, the proper measures for goodness of fit for the spatial regression models are the Log-Likelihood, Akaike Information Criterion (AIC) and Schwartz Criterion (SC) (Anselin, 2005). Comparing Table 5 with Table 3, one can easily see that the fit of the two linear models has improved a lot when the spatial error variables $(\lambda)$ were incorporated in the regression. The Log-Likelihood increases from -204.42 (for OLS model) to -198.75 for ecological footprint of consumption, and from -245.11 (for OLS model) to -199.12 for ecological footprint of production. Compensating the improved fit for spatial error specification, the AIC and SC both decrease relative to OLS, again suggesting an improvement of fit for our new estimation scheme.

Although inclusion of spatial error terms have improved the model fit substantially, it still cannot make the spatial dependence go away. As shown in Table 5, the low probability of the Likelihood Ratio test suggests that there is still a spatial autocorrelation in the residuals of the spatial error models (Pace and Barry, 1997; LeSage, 1999; Anselin, 2005). Given this, we incorporated other covariates that contain spatial lags in both dependent and independent variables into the re-estimation to eliminate spatial dependence in the residuals of spatial error models. Results are presented in Table 6.

Results show that all of the spatially lagged explanatory variables, except W_BIO for ecological footprint of consumption, are statistically significant. However, there is interesting difference in the sign of the regression coefficients among spatially lagged variables: the spatially lagged independent variables are uniformly negative, while the spatially lagged dependent variables are uniformly positive. The positive sign of the lagged dependent variable coefficients suggests that an increase in the ecological footprint of consumption (or production) in adjacent neighborhood countries would lead to an increase in the ecological footprint of consumption (or production) in the home country. As shown in Table 6 , a one percent change in neighborhood average per capita consumption footprint results in a $0.26 \%$ change in per capita consumption footprint in the home country. For the production footprint the corresponding figure is 0.46 . These results reveal the surprising extent to which changes in domestic ecological footprints, consumed or produced, per capita are influenced by changes in footprints per capita in neighboring countries. It seems likely that changes of environmental performance might result from changes in neighboring countries, which implying that neighboring countries always mimic each other when they strategically developing environmental policies and standards. Indeed, government officials and bureaucrats are also constantly assessing policy against those of their neighbors in order to reduce the costs of decision-making and to legitimize their actions, particularly when there is uncertainty regarding the effects of those policies (Maddison, 2006). Thus, to some extent, changes in domestic environmental performance that were usually attributed to in-country value are really due to the neighborhoods.

Contrary to the spatial effects of lagged footprint variables, the lagged income variables (W_GDP) would have a negative spatial impact on the ecological footprint of both consumption and production. Table 6 reveals that a one percent increase in neighborhood income causes a $0.0602 \%$ decrease in per capita ecological footprint of consumption, and a $0.1042 \%$ decrease in per capita ecological footprint of production. It appears that an increase in income in the neighborhood countries would lead to a decrease in the ecological footprint of both consumption and production in the home country. Concern has frequently been expressed that the diffusion of cleaner production technology and increasing environmental awareness playing important roles in improving a country's environmental quality, here we find evidence to suggest that there is an inherent link between one country's environment and its neighbor's economy.

Similarly to the lagged income variables, the negative sign of the lagged biocapacity variable coefficients suggest that having highbiocapacity neighbors is associated with having lower domestic resources use. However, the spatially lagged variable of biocapacity is only statistically significant for the ecological footprint of production. It might convey the idea that a country might to secure sustainable development - in the sense of not depleting its own stock of capital assets - at the cost of procuring ecological resources in neighboring countries. As indicated by Rothman (1998b), trade liberalization or openness provides means through which domestic production and consumption can become disassociated. Thus, it is perfectly possible for a country to support its economic development and reduce its environmental degradation by obtaining the natural resources from countries with high biocapacity. Table 6 shows that the lagged biocapacity variable is not statistically significant for the consumption footprints, indicating that the biocapacity in the neighborhood has no obvious impacts on the consumption in the home country.

In comparison with the neighborhood effects, a country's domestic income and bocapacity play a more notable role in determining the degree of environmental disturbance. For example, the domestic income elasticity of production footprints is 0.1904 , while the neighboring income elasticity of production footprints is only 0.0602 (Table 6). Moreover, the magnitude of non-spatially lagged 
Table 6

Spatial Durbin models for ecological footprint of consumption and production.

\begin{tabular}{|c|c|c|c|}
\hline & $\mathrm{EFC}$ & $\mathrm{EFC}$ & EFP \\
\hline Constant & $\begin{array}{l}0.7316^{* * *} \\
(4.9401)\end{array}$ & $\begin{array}{l}0.8367^{* * *} \\
(5.7826)\end{array}$ & $\begin{array}{l}0.2629^{*} \\
(1.6749)\end{array}$ \\
\hline GDP & $\begin{array}{l}0.1837^{* * *} \\
(15.5117)\end{array}$ & $\begin{array}{l}0.1904^{* * *} \\
(15.6417)\end{array}$ & $\begin{array}{l}0.1972^{* * *} \\
(13.8493)\end{array}$ \\
\hline BIO & $\begin{array}{l}0.0766^{* *} \\
(3.2669)\end{array}$ & & $\begin{array}{l}0.2491^{* * *} \\
(8.7714)\end{array}$ \\
\hline W_GDP & $\begin{array}{l}-0.0574^{*} \\
(-2.4894)\end{array}$ & $\begin{array}{l}-0.0602^{*} \\
(-2.510)\end{array}$ & $\begin{array}{l}-0.1042^{* * *} \\
(-4.5512)\end{array}$ \\
\hline W_BIO & $\begin{array}{l}-0.0325 \\
(-0.8259)\end{array}$ & & $\begin{array}{l}-0.1128^{* *} \\
(-2.2079)\end{array}$ \\
\hline$\rho$ & $\begin{array}{l}0.2619^{* *} \\
(2.7981)\end{array}$ & $\begin{array}{l}0.2660^{* *} \\
(2.8826)\end{array}$ & $\begin{array}{l}0.4520^{* * *} \\
(5.4878)\end{array}$ \\
\hline Observations & 150 & 150 & 150 \\
\hline$R^{2}$ & 0.7664 & 0.7499 & 0.7416 \\
\hline Log-likelihood & -148.7238 & -154.5411 & -181.4790 \\
\hline AIC & 309.4476 & 317.0822 & 374.9580 \\
\hline SC & 327.1247 & 329.1247 & 393.0218 \\
\hline Likelihood ratio & 1.7277 & 1.8812 & 2.3793 \\
\hline
\end{tabular}

Spatial weight matrix = higher adjacency.

$\rho$ is the spatially lagged dependent variable (W_EFC or W_EFP).

${ }^{*} p<0.05$.

** $p<0.01$.

*** $p<0.001$.

variable coefficients shows that the ecological footprint of consumption was more sensitive to income than biocapacity, while the ecological footprint of production was more sensitive to biocapacity than income. This would seem to suggest that, to some extent, a high level of consumption footprint is necessary for a high level of domestic income, while a high level of production footprint is necessary for a high level of domestic biocapacity.

The last results presented in Table 6 suggest that the incorporation of lagged dependent and independent variables has increased model explanatory power over the spatial error specifications. The improvement of fit is expected because the spatial spillovers effects have been captured for the spatial Durbin models. Note also, The Likelihood Ratio tests of spatial error dependence achieve insignificant values for both consumption and production footprint, implying that the previously failed independent residuals test for spatial error and OLS models has been corrected in the spatial Durbin models. Therefore, it seems that the spatial Durbin models were more suitable for estimating the EKC for ecological footprint at the global level.

\section{Conclusions}

Compared with conventional estimation techniques, the spatial econometric approach could provide researches with a means to explore the question of whether or not the domestic environmental performance is dependent on the characteristics of neighboring states. Thus, this paper introduced a spatial econometric approach to re-examine the relationship between economic growth and environmental impact for indicator of ecological footprint. Based on Moran's I statistic, we found a significant spatial autocorrelation present in the data set of 150 countries' ecological footprint used in our study. This violates the assumption of independence of observations which is a serious concern for traditional OLS regression tests and leads to an inappropriate model specification. This finding may provide a possible explanation of why estimating the EKC with cross-sectional data always results in evidence of parameter instability. For this reason, the incorporation of spatially lagged variables and the estimation of spatial error and Durbin models could offer greater explanatory power than the classical OLS models.

In our results, there is no statistically significant support for an inverted U-shape EKC hypothesis for the indictor of ecological footprint (both consumption and production). Taking into account the potentially spatial dependence of the dataset, we have provided new insights into the nature of spillovers that take place in the space system of global environmental performance and change. Our findings suggest that the domestic ecological footprint of consumption (or production) was obviously influenced by the ecological footprint of consumption (or production), income and biocapacity in neighborhood countries. Trade openness, technological diffusion, capital inflows, and common political, economic and environmental policies are the potential factors that may lead to the occurrences of spatial interactions. Moreover, comparing the coefficients of non-spatially lagged variables, we found that the consumption footprint is more sensitive to domestic income, while production footprint is more sensitive to domestic biocapacity. This is often unnoticed in EKC hypothesis analyses that focus exclusively on the consumption-based or production-based indictors.

We are aware that this paper is merely an initial attempt to examining the EKC hypothesis using the spatial econometric techniques and the study could be completed with a more detailed analysis with other spatial weights matrix defined on geographic and non-geographic measures of connectivity. Doing so would give a clearer answer that whether or not the nontraditional contiguity provides a better representation of spatial relationships among countries than the common contiguity criterion used in this analysis. Moreover, it seems clear that our work could also be improved in the coming period by using dynamic panel data models to better understand the relationships between economic activity and environmental impact. These are just a few of the potential future lines of research revealed by our study.

\section{Acknowledgments}

This study was funded by the National Natural Science Foundation of China (Grant No. 41001378) and the Promotive Research Fund for Excellent Young and Middle-aged Scientisits of Shandong Province (Grant No. BS2012HZ026). We would like to express our gratitude to two anonymous referees whose comments and suggestions were very helpful. All remaining errors and opacity are the sole responsibility of the authors. 


\section{References}

Anselin, L., 1988. Model validation in spatial econometrics: a review and evaluation of alternative procedures. Int. Reg. Sci. Rev. 11 (3), 279-316.

Anselin, L., 2001. Spatial effects in econometric practice in environmental and resource economics. Am. J. Agric. Econ. 83 (3), 705-710.

Anselin, L., 2005. Exploring Spatial Data with GeoDa: A Workbook, Revised Version. University of Illinois, Urbana-Champaign, Urbana, IL, Available at the http://www.csiss.org/clearinghouse/GeoDa

Anselin, L., Bera, A., 1998. Spatial dependence in linear regression models with an introduction to spatial econometrics. In: Ullah, A., Giles, D.E. (Eds.), Handbook of Applied Economic Statistics. Marcel Dekker, New York, pp. 237-289.

Anselin, L., Griffith, D.A., 1988. Do spatial effects really matter in regression analysis? Reg. Sci. 65, 11-34.

Anselin, L., Rey, S.J., 1991. Properties of tests for spatial dependence in linear regression models. Geograph. Anal. 23 (2), 112-131.

Anselin, L., Rey, S.J., 1997. Introduction to the special issue on spatial econometrics. Int. Reg. Sci. Rev. 20 (1-2), 1-7.

Antweiler, W., Copeland, B.R., Taylor, M.S., 2001. Is free trade good for the environment? Am. Econ. Rev. 91 (4), 877-908.

Arrow, K., Bolin, B., Costanza, R., Folke, C., Holling, C.S., Janson, B., Levin, S., Maler, K., Perrings, C., Pimental, D., 1995. Economic growth, carrying capacity, and the environment. Science 268 (28), 520-521.

Auci, S., Becchetti, L., 2006. The instability of the adjusted and unadjusted environmental Kuznets curves. Ecol. Econ. 60 (1), 282-298.

Bagliani, M., Bravo, G., Dalmazzone, S., 2008. A consumption-based approach to environmental Kuznets curves using the ecological footprint indicator. Ecol. Econ. 65 (3), 650-661.

Beckerman, W., 1992. Economic growth and the environment: whose growth? Whose environment? World Develop. 20 (4), 481-496.

Bertinellia, L., Stroblb, E., Zoua, B., 2008. Economic development and environmental quality: a reassessment in light of nature's self-regeneration capacity. Ecol. Econ. $66(2-3), 371-378$.

Bhattarai, M., Hammig, M., 2001. Institutions and the environmental Kuznets curve for deforestation: a cross-country analysis for Latin America, Africa, and Asia. World Develop. 29 (6), 995-1010.

Bockstael, N.E., 1996. Modeling economics and ecology: the importance of a spatial perspective. Am. J. Agric. Econ. 78 (5), 1168-1180.

Canas, A., Ferrao, P., Conceicao, P., 2003. A new environmental Kuznets curve? Relationship between direct material input and income per capita: evidence from industrialised countries. Ecol. Econ. 46 (2), 217-229.

Caviglia-Harris, J.L., Chambers, D., Kahn, J.R., 2009. Taking the U out of Kuznets: a comprehensive analysis of the EKC and environmental degradation. Ecol. Econ. 68 (4), 1149-1159.

Cole, M.A., 2004. Trade, the pollution haven hypothesis and environmental Kuznets curve: examining the linkages. Ecol. Econ. 48 (1), 71-81.

Cropper, M., Charles, G., 1994. The interaction of population growth and environmental quality. Am. Econ. Rev. Proc. 84 (2), 250-254.

Culas, R.J., 2007. Deforestation and the environmental Kuznets curve: an institutional perspective. Ecol. Econ. 61 (2-3), 429-437.

Dinda, S., 2004. Environmental Kuznets curve hypothesis: a survey. Ecol. Econ. 49 (4), 431-455.

Ewing, B., Goldfinger, S., Wackernagel, M., Stechbart, M., Rizk, S.M., Reed, A., Kitzes, J., 2008. The Ecological Footprint Atlas 2008. Global Footprint Network, Oakland

Galeotti, M., Lanza, A., Pauli, F., 2006. Reassessing the environmental Kuznets curve for $\mathrm{CO}_{2}$ emissions: a robustness exercise. Ecol. Econ. 57 (1), 152-163.

George, H., Nickolaos, T., 2011. Regional environmental efficiency and economic growth: NUTS2 evidence from Germany, France and the UK. MPRA Paper. University of Thessaly, Available at the http://mpra.ub.uni-muenchen.de/33698

Giacomini, R., Granger, C.W.J., 2004. Aggregation of space-time processes. J. Econometrics $118,7-26$.

Goodchild, M., Anselin, L., Appelbaum, R., Harthorn, B.H., 2000. Towards spatially integrated social science. Int. Reg. Sci. Rev. 23 (2), 139-159.

Grether, J.M., Melo, J.de., 2002. Globalization and dirty industries: do pollution havens matter? Department d'economie and Politique, Neuchatel, Switzerland, Mimeo.

Grossman, G.M., Krueger, A.B., 1996. The inverted-U: what does it mean? Environ. Develop. Econ. 1 (1), 119-122.
Kaufmann, R.K., Davidsdottir, B., Garnham, S., Pauly, P., 1998. The determinants of atmospheric $\mathrm{SO}_{2}$ concentrations: reconsidering the environmental Kuznets curve. Ecol. Econ. 25 (2), 209-220.

Kearsley, A., Riddel, M., 2010. A further inquiry into the pollution haven hypothesis and the environmental Kuznets curve. Ecol. Econ. 69 (4), 905-919.

Leitao, A., 2010. Corruption and the environmental Kuznets curve: empirical evidence for sulfur original research article. Ecol. Econ. 69 (11), 2191-2201.

LeSage, J.P., 1999. The Theory and Practice of Spatial Econometrics. University of Toledo, MN, Available at the http://www.spatial-econometrics.com/ html/sbook.pdf

Liddle, B., 2001. Free trade and the environment-development system. Ecol. Econ. 39 (1), 21-36.

Liu, X.Z., Heilig, G.K., Chen, J.M., Heino, M., 2007. Interactions between economic growth and environmental quality in Shenzhen, China's first special economic zone. Ecol. Econ. 62 (3-4), 559-570.

Maddison, D., 2006. Environmental Kuznets curves: a spatial econometric approach. J. Environ. Econ. Manage. 51 (2), 218-230.

Managi, S., 2006. Are there increasing returns to pollution abatement? Empirical analytics of the environmental Kuznets curve in pesticides. Ecol. Econ. 58 (3), 617-636.

McPherson, M.A., Nieswiadomy, M.L., 2005. Environmental Kuznets curve: threatened species and spatial effects. Ecol. Econ. 55 (3), 395-407.

Pace, R.K., Barry, R., 1997. Quick computation of spatial autoregressive estimators. Geograph. Anal. 29, 232-246.

Panayotou, T., 1999. The economics of environments in transition. Environ. Develop. Econ. 4 (4), 401-412.

Pandit, R., Laband, D.N., 2007. Spatial autocorrelation in country-level models of species imperilment. Ecol. Econ. 60 (3), 526-532.

Pasche, M., 2002. Technical progress, structural change, and the environmental Kuznets curve. Ecol. Econ. 42 (3), 381-389.

Ramirez, M., Loboguerrero, A., 2002. Spatial dependence and economic growth: evidence from a panel of countries. Borradores de Economia Working Paper No. 206. Available at the http://www.banrep.gov.co/docum/ftp/borra206.pdf

Raymond, J.G.M.F., Arno, J.V.D.V., 2003. Spatial econometric data analysis: moving beyond traditional models. Int. Reg. Sci. Rev. 26 (3), 223-243.

Roca, J., 2003. Do individual preferences explain environmental Kuznets curve? Ecol. Econ. 45 (1), 3-10.

Romero-Avila, D., 2008. Questioning the empirical basis of the environmental Kuznets curve for $\mathrm{CO}_{2}$ : new evidence from a panel stationarity test robust to multiple breaks and cross-dependence. Ecol. Econ. 64 (3), 559-574.

Rothman, D., 1998a. Environmental Kuznets curves - real progress or passing the buck? A case for consumption-based approaches. Ecol. Econ. 25 (2), 177-194.

Rothman, D.S., 1998b. Environmental Kuznets curves - real progress or passing the buck? A case for consumption-based approaches. Ecol. Econ. 25 (2), 177-194.

Rupasingha, A., 2009. Value-added agricultural enterprises and local economic performance. Appl. Econ. Perspect. Policy 31 (3), 511-534.

Rupasingha, A., Goetz, S.J., Debertin, D.L., Pagoulatos, A., 2004. The environmental Kuznets curve for US counties: a spatial econometric analysis with extensions. Reg. Sci. 83 (2), 407-424.

Selden, T.M., Song, D., 1995. Neoclassical growth, the $J$ curve for abatement, and the inverted $U$ curve for pollution. J. Environ. Econ. Manage. 29 (2), $162-168$.

Shafik, N., Bandyopadhyay, S., 1992. Economic Growth and Environmental Quality: Time Series and Cross-country Evidence. Background Paper for the World Development Report. World Bank, Washington, DC.

Stern, D.I., 2004. The rise and fall of the Environmental Kuznets curve. World Develop. 32 (8), 1419-1439.

Suri, V., Chapman, D., 1998. Economic growth, trade and energy: implications for the environmental Kuznets curve. Ecol. Econ. 25 (2), 195-208.

Vukina, T., Beghin, J.C., Solakoglu, E.G., 1999. Transition to markets and the environment: effects of the change in the composition of manufacturing output Environ. Develop. Econ. 4 (4), 582-598.

World Bank, 2007. World Development Indicators 2002. The World Bank, Washington, DC.

Ying, L.G., 2003. Understanding China's recent growth experience: a spatial econometric perspective. Ann. Reg. Sci. 37 (4), 613-628. 